\title{
Expression of CD38 in myeloma bone niche: A rational basis for the use of anti-CD38 immunotherapy to inhibit osteoclast formation
}

\author{
Federica Costa ${ }^{1, *}$, Denise Toscani ${ }^{1, *}$, Antonella Chillemi ${ }^{2}$, Valeria Quarona ${ }^{2}$, Marina \\ Bolzoni $^{1}$, Valentina Marchica ${ }^{1,6}$, Rosanna Vescovini ${ }^{3}$, Cristina Mancini ${ }^{4}$, Eugenia \\ Martella ${ }^{4}$, Nicoletta Campanini ${ }^{4}$, Chiara Schifano ${ }^{5}$, Sabrina Bonomini ${ }^{5}$, Fabrizio \\ Accardi 1,5 , Alberto L. Horenstein ${ }^{2}$, Franco Aversa ${ }^{1,5}$, Fabio Malavasi ${ }^{2}$ and Nicola \\ Giuliani ${ }^{1,5,6}$ \\ ${ }^{1}$ Department of Medicine and Surgery, University of Parma, Parma, Italy \\ ${ }^{2}$ Laboratory of Immunogenetics, Department of Medical Sciences and CeRMS, University of Torino, Torino, Italy \\ ${ }^{3}$ Clinical Medicine Unit, Department of Medicine and Surgery, University of Parma, Parma, Italy \\ ${ }^{4}$ Pathology, "Azienda Ospedaliero-Universitaria di Parma", Parma, Italy \\ ${ }^{5}$ Hematology and BMT Center, "Azienda Ospedaliero-Universitaria di Parma", Parma, Italy \\ ${ }^{6}$ CoreLab, "Azienda Ospedaliero-Universitaria di Parma", Parma, Italy \\ *These authors contributed equally to this work
}

Correspondence to: Nicola Giuliani, email: nicola.giuliani@unipr.it

Keywords: multiple myeloma, CD38, osteoclast, bone disease, immunotherapy

Received: October 27, $2016 \quad$ Accepted: April 29, $2017 \quad$ Published: May 16, 2017

Copyright: Costa et al. This is an open-access article distributed under the terms of the Creative Commons Attribution License 3.0 (CC BY 3.0), which permits unrestricted use, distribution, and reproduction in any medium, provided the original author and source are credited.

\section{ABSTRACT}

It is known that multiple myeloma (MM) cells express CD38 and that a recently developed human anti-CD38 monoclonal antibody Daratumumab mediates myeloma killing. However, the expression of CD38 and other functionally related ectoenzymes within the MM bone niche and the potential effects of Daratumumab on bone cells are still unknown. This study firstly defines by flow cytometry and immunohistochemistry the expression of CD38 by bone marrow cells in a cohort of patients with MM and indolent monoclonal gammopathies. Results indicate that only plasma cells expressed CD38 at high level within the bone niche. In addition, the flow cytometry analysis shows that CD38 was also expressed by monocytes and early osteoclast progenitors but not by osteoblasts and mature osteoclasts. Indeed, CD38 was lost during in vitro osteoclastogenesis. Consistently, we found that Daratumumab reacted with CD38 expressed on monocytes and its binding inhibited in vitro osteoclastogenesis and bone resorption activity from bone marrow total mononuclear cells of MM patients, targeting early osteoclast progenitors. The inhibitory effect was not observed from purified $\mathrm{CD} 14^{+}$cells, suggesting an indirect inhibitory effect of Daratumumab. Interestingly, all-trans retinoic acid treatment increased the inhibitory effect of Daratumumab on osteoclast formation.

These observations provide a rationale for the use of an anti-CD38 antibodybased approach as treatment for multiple myeloma-induced osteoclastogenesis.

\section{INTRODUCTION}

Multiple myeloma (MM) is an incurable plasma cell (PC) malignancy leading to osteolytic bone disease, due to an increased formation and activity of osteoclasts (OCs) and a decreased osteoblastogenesis [1-3]. The relationship between MM cells and the bone cells, OCs and osteoblasts (OBs), plays a critical role both in the progression of $\mathrm{MM}$ and in the development of osteolytic bone lesions. Malignant PCs highly express surface molecules involved in the adhesion to the bone marrow (BM) microenvironment cells and in the development of bone lesions $[4,5]$. 
Among the adhesion molecules, CD38 is highly expressed by MM cells [6-9] although its pathophysiological role in MM and in MM-induced bone disease is apparently more complex. CD38 is a $45-\mathrm{kDa}$ type II transmembrane glycoprotein, widely expressed by several cell types [8], which plays a dual role as a receptor and ectoenzyme [10]. It is involved in T cell activation and proliferation, $\mathrm{B}$ cell differentiation and cell adhesion through the non-substrate ligand CD31 [11]. Moreover, CD38 acts as metabolic sensor that converts NAD+ to cADPR and ADPR and NADP+ to NAADP+, according to $\mathrm{pH}$ status.[12] CD38 acts in conjunction with the other ectoenzymes CD73 and CD203a, in the alternative axis of extracellular production of the immunosuppressive factor adenosine (ADO), bypassing the canonical pathway mediated by CD39 [13]. In addition to the transmembrane arrangement, a CD38 soluble form also exists, probably as a result of enzymatic cleavage of the cell-surface protein, both in normal and pathological fluids [14] and in exosomes [15]. CD38 is also involved in the remodelling of the adult skeleton in mice [16], being expressed on murine OCs [1, 17] and OBs [18]. Moreover, Sun L et al. showed that rabbit OCs expressed CD38 on plasma membrane, with ADP ribosyl cyclase activity, and an antiCD38 agonist antibody inhibited bone resorption [17]. However, the expression of CD38 by human OCs and OBs has not yet been reported.

Daratumumab (DARA), a high-affinity human IgG1 $\kappa$ anti-CD38 monoclonal antibody (mAb), showed encouraging results in the treatment of patients with relapsed or refractory disease [19-21]. It has a broadspectrum killing activity that includes complementdependent cytotoxicity (CDC), antibody-dependent cell-mediated cytotoxicity (ADCC), antibody-dependent cellular phagocytosis (ADCP), apoptosis and, at least in part, modulation of CD38 enzymatic activity [22]. A study from Nijhof IS et al. [23] showed that DARA-induced $\mathrm{CDC}$ and ADCC were strictly associated to the level of CD38 and the pre-treatment with all-trans retinoic acid (ATRA) up-regulated CD38 expression in MM cells, enhancing DARA effects in a humanized MM mouse model [23].

Microvesicles (MVs) are a class of extracellular vesicles shed by different cell types under physiological conditions. Moreover, patients with different types of cancer were reported to have high number of circulating MVs suggesting their direct involvement in modulating cell communication within the tumor microenvironment. More importantly, the hypoxic microenvironment may accelerate the release of MVs into the surrounding environment promoting tumor growth, invasion and angiogenesis [24, 25]. Recently, Horenstein AL et al. [26] have shown that DARA ligation on MM cells was followed by aggregation, polarization, and release of MVs, extrusions of cell membrane that bear CD38 on the surface, whose fate needs to be defined [26].
Currently, the expression of CD38 and its related ectoenzymes by OCs and OBs in MM BM niche and the effects of DARA on MM-induced bone remodelling alterations are still unknown and were investigated in this study.

\section{RESULTS}

\section{Expression profiling of CD38 in the bone niche of MM patients}

The expression pattern of CD38 was evaluated by flow cytometry on primary $\mathrm{CD} 138+$ purified from $16 \mathrm{MM}$ patients, human myeloma cell lines (HMCLs) and microenvironment cell lines. All primary MM cells expressed CD38 at high level, as well as HMCLs (except for INA-6). The stromal cell line human stromal cell line (HS5) expressed CD38 weakly in contrast to human osteoblastic cell lines human pre-osteocytic cell line (HOB-01) and human osteoblast-like cells (HOBIT) which did not express CD38 at surface level (Figure 1A). On the other hand, CD38 expression was present at cytoplasmic level in the same cell lines (Figure 1B).

The immunohistochemistry analysis performed on bone biopsies of MM patients confirmed the immunophenotype data. Specifically, MM cells expressed CD38 at high level (Figure 2A-2B), whereas OBs (Figure 2B, 2ii), OCs (Figure 2B, 2iii-iv) and endothelial cells did not. Moreover, the expression profiling of the nonsubstrate ligand CD31 and that of other ectoenzymes of the adenosinergic pathway, as CD39, CD73 and CD203a was also evaluated. Results are reported in Supplementary Tables 1,2 and 3. Illustrative pictures of selected ectoenzymes distribution on bone biopsies of MM patients are showed in the Supplementary Figure 1.

\section{CD38 is expressed by monocytes and early OC progenitors but lost during the in vitro osteoclastogenesis}

We evaluated CD38 expression by monocytes and during in vitro osteoclastogenesis from $\mathrm{CD} 14^{+}$cells, either at cytoplasmatic levels by western blotting or surface levels by flow-cytometry. We found that both monocytes and mature OCs expressed CD38 at cytoplasmatic level (Figure 3A). Conversely, the flow-cytometry analysis showed that monocytes were positive for CD38 and that its expression decreased on day 7 , with a further reduction on day 14 of OC differentiation (Figure 3B, left panels) suggesting that mature OCs lost CD38 surface expression. Interestingly, CD38 levels increased during in vitro osteoclastogenesis in the presence of high concentration $(20 \mathrm{nM})$ of ATRA but not at low concentration $(0.1 \mathrm{nM})$ (Figure 3B).

Confocal analysis confirmed that mature OCs did not express CD38 on their surface (Figure 4A). Lastly, we confirmed that OBs were negative for surface CD38 (Figure 4B). 


\section{DARA inhibited OC formation, targeting early OC progenitors}

Considering the CD38 expression profiling, we checked the ability of DARA to bind monocytes compared to other peripheral blood (PB) cell populations. We performed a flow cytometry assay with FITC-conjugated DARA on Healthy donor (HD) PB mononuclear cells (PBMCs) and demonstrated that DARA binds monocytes and NK cells. However, DARA binding was not detectable on $\mathrm{T}$ cells and $\mathrm{B}$ cells (Figure 4C), consistent with the CD38 expression previously described on monocytes.

Thereafter, to determine the potential effect of DARA on osteoclastogenesis, we performed in vitro OC differentiation from mononuclear cells (MNCs) of $13 \mathrm{MM}$ patients, in the presence of DARA (or isotype control IgG) at seeding (day 0 ) or after 10 days of culture (day 10). When compared with cultures with IgG alone, the presence of DARA reduced the number of OCs when added on day 0 (two-tailed, paired Student's $t$-test, DARA $10 \mu \mathrm{g} / \mathrm{ml}$ vs IgG and DARA $25 \mu \mathrm{g} / \mathrm{ml}$ vs IgG: $p<0.0001$ ) (Figure 5A-5B). On the contrary, DARA did not inhibit OCs formation when it was added on day 10 , indicating the lack of effects on late OC progenitors and mature OCs (Figure 5A-5B). The inhibitory effect of DARA on OCs formation was not observed when OCs were differentiated from purified $\mathrm{CD} 14^{+}$cells (Figure 5C), consistent with DARA mechanisms of action in MM cells mediated by effector cells [22]. Treatment with DARA also decreased the area of osteoclast bone resorption pits and OC resorption activity
(Figure 6) after both 14 (two-tailed, paired Student's $t$-test, DARA $10 \mu \mathrm{g} / \mathrm{ml}$ vs IgG: $p=0.0004$; DARA $25 \mu \mathrm{g} / \mathrm{ml}$ vs IgG: $p=0.0003$ ) and 21 days of treatment (twotailed, paired Student's $t$-test, DARA $10 \mu \mathrm{g} / \mathrm{ml}$ vs IgG: $p=0.0002$; DARA $25 \mu \mathrm{g} / \mathrm{ml}$ vs IgG: $p=0.0001$ ).

In addition, we found that the inhibitory effect of DARA in OC differentiation was not mediated by soluble factors secreted by MM cells, since the conditioned medium (CM) of HMCLs previously pre-treated with DARA did not inhibited OC in vitro formation (data not shown). Lastly, we also investigated the potential effect of DARA-induced MVs on OC formation and we performed in vitro osteoclastogenesis from MM MNCs, in the presence of MVs isolated from the HMCLs RPMI8226 and JJN3, treated with DARA $200 \mu \mathrm{g} / \mathrm{ml}$ or IgG. No significant differences in OC number were observed in the presence of DARA-induced MVs compared to IgGinduced MVs (Supplementary Figure 2).

\section{ATRA treatment increased DARA effects on OC formation}

Since literature data showed that ATRA improves DARA-mediated ADCC and CDC against MM cells [23], we investigated the effect of DARA in combination with ATRA on in vitro osteoclastogenesis. Initial experiments were performed to evaluate the effect of ATRA $(0.01 \mathrm{nM}-200 \mathrm{nM})$ on OCs differentiated from MNCs of MM patients for 21 days. ATRA caused a dose-dependent inhibition of osteoclastogenesis with a minimal effect at
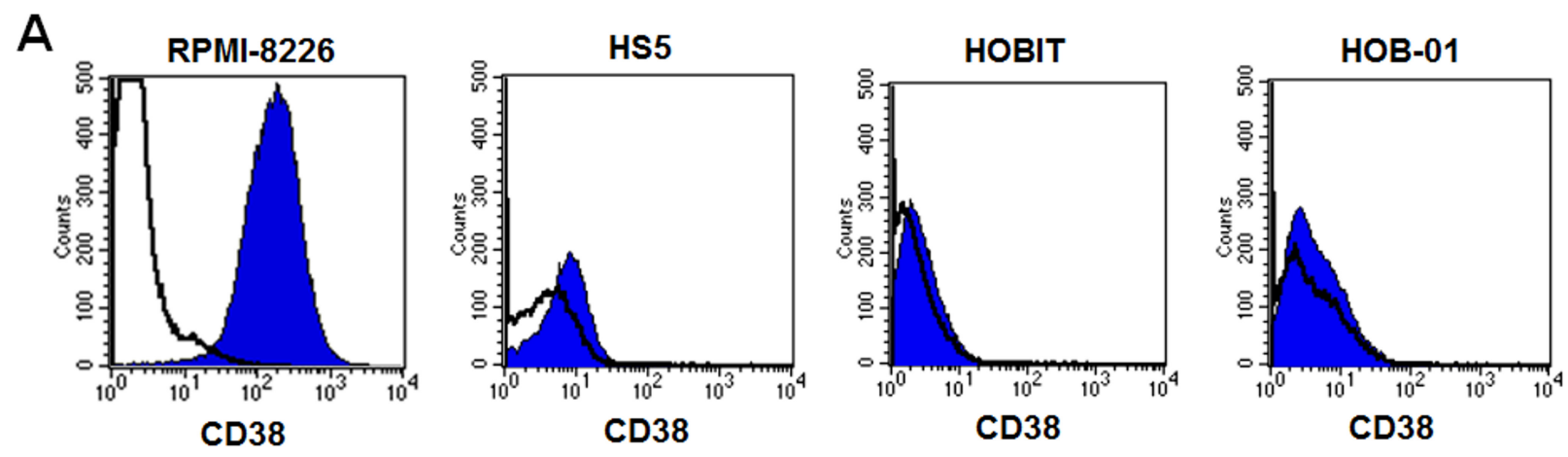

B

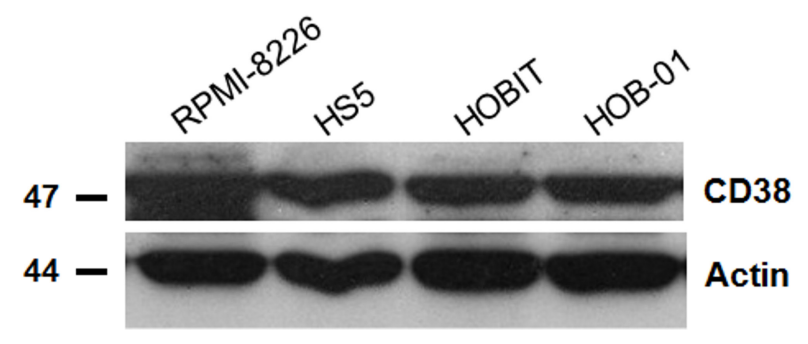

Figure 1: CD38 was present in the cytoplasm but it was not expressed at the surface by stromal and osteoblastic cells. (A) CD38 expression was evaluated on HMCL RPMI-8226, on human stromal cell line (HS5), on immortalized human osteoblast-like cells (HOBIT) and on human pre-osteocytic cell line (HOB-01) by flow-cytometry. (B) CD38 citoplasmatic expression was evaluated on the same cells by western blot. HMCL RPMI-8226 was used as positive control and $\beta$-actin as internal control. 
$0.1 \mathrm{nM}$. Indeed, higher concentration induced a drastic reduction of osteoclasts (Supplementary Figure 3). In order to assess a possible combinatory effect, we used ATRA at $0.1 \mathrm{nM}$ and $20 \mathrm{nM}$ for further experiments.

OC number was significantly reduced in the combined treatment condition (DARA $25 \mu \mathrm{g} / \mathrm{ml}$ and ATRA $0.1 \mathrm{nM}$ ) compared to the single agent treatment (one-way ANOVA, DARA $25 \mu \mathrm{g} / \mathrm{ml}$ plus ATRA $0.1 \mathrm{nM}$ vs DARA $25 \mu \mathrm{g} / \mathrm{ml}$ : $p<0.01$; DARA $25 \mu \mathrm{g} / \mathrm{ml}$ plus ATRA $0.1 \mathrm{nM}$ vs ATRA $0.1 \mathrm{nM}: p<0.01$ ) (Figure 7A-7B). On the other hand, the treatment with ATRA at $20 \mathrm{nM}$ showed a drastic effect on OCs which made the study of the effects in combination with DARA impossible. Yet, DARA $25 \mu \mathrm{g} / \mathrm{ml}$ plus ATRA $0.1 \mathrm{nM}$ was used to treat purified $\mathrm{CD}^{+} 4^{+}$cells under osteoclastogenic conditions. The treatment did not affect the number of OC compared with the single agent treatment confirming the importance of effector cells in the system.

\section{DISCUSSION}

The use of the CD38 molecule as a target for antibody-mediated treatment of MM [27] provided an opportunity to access evidence from in vivo applications. The anti-MM effect of DARA has been widely described. [19] Some issues, stemmed from the fact that the target molecule is expressed not only by the tumor but also by effectors and inhibitory cells, are still unresolved [28]. Several studies have reported the CD38 involvement in bone remodelling, in mice and rabbit models [16, 17], where both OBs and OCs expressed CD38. However, reports on CD38 expression by human OBs and OCs are still very limited [18, 29-31].

It has been reported that CD38 is also involved, in conjunction with other ectoenzymes such as CD73 and CD203a, in the alternative production of ADO.

\section{A}

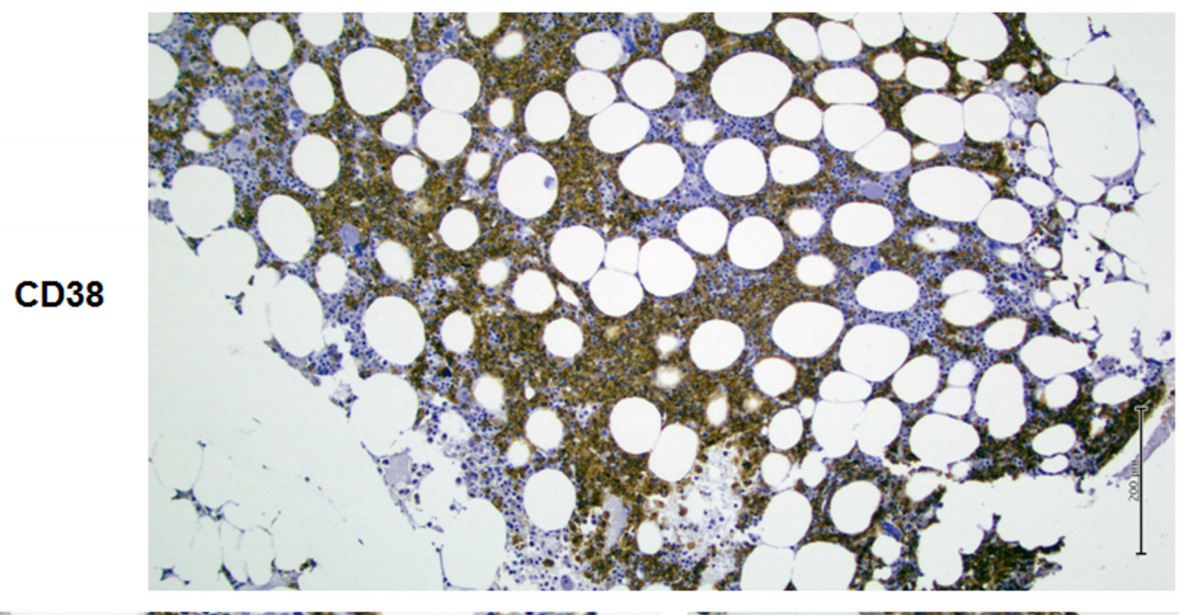

B
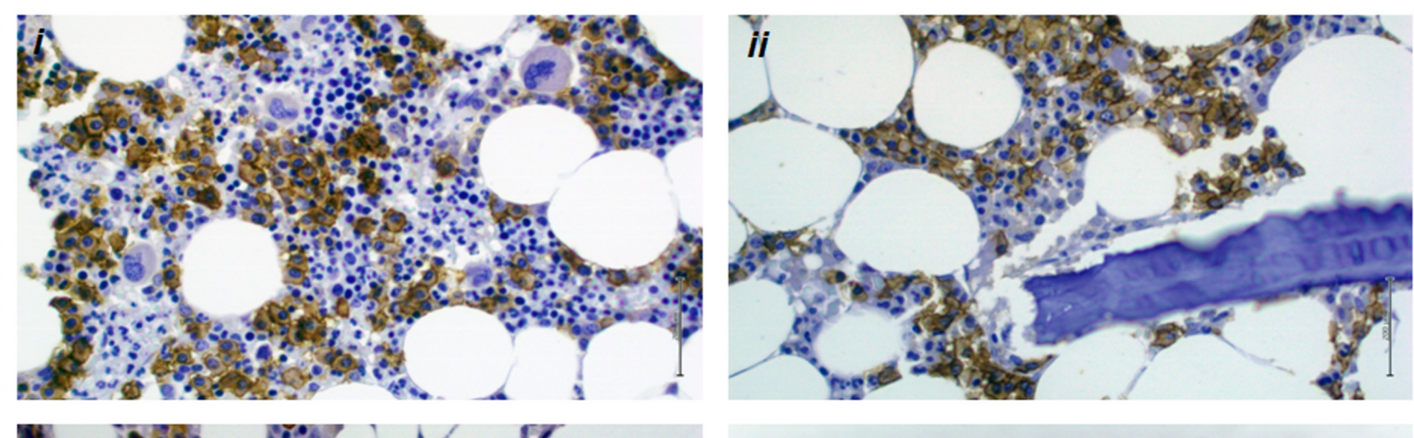

CD38
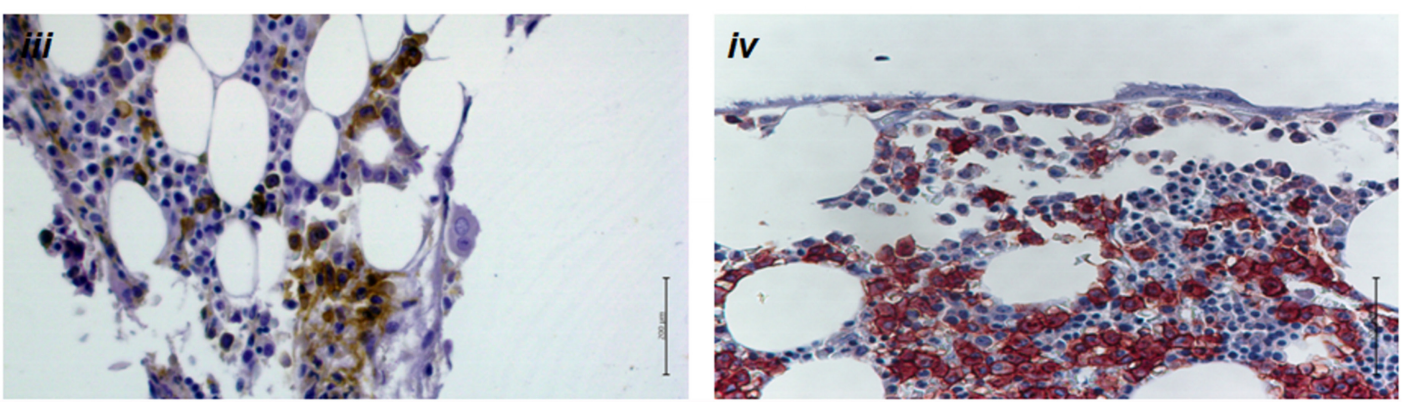

Figure 2: CD38 expression on bone biopsies of MM patients. CD38 immunohistochemistry was performed on bone biopsies obtained from MM patients. Photos show representative MM patients. A strong CD38 immunostaining positivity was detected in PCs (A, B i-iv). OBs (B ii) and OCs (B iii and $i v$ ) were negative. The immunoperoxidase technique ( $i-i i i)$ and Fast Red technique (iv) were used to reveal immunostaining. Original magnification $10 \times(\mathrm{A})$ and $40 \times(\mathrm{B})$. 
Horenstein AL. et al. [32] recently have shown that this ectoenzymatic network is active even in MM bone niche and that ADO levels correlate with disease aggressiveness and ISS staging of MM patients [32].

The study firstly focused on the evaluation of the expression profiling of CD38 on primary CD138 purified from MM patients. All MM samples expressed CD38 as well as HMCLs. We observed that human stromal and osteoblastic cell lines did not express CD38. However, OBs expressed CD38 at cytoplasmatic levels consistent with CD38 localization in endoplasmic reticulum and nuclear membrane, as found in osteoblastic cell lines by Sun L et al. [18]. Moreover, a study from Romanello M et al. [29] showed that OBs display ADP-ribosyl cyclase/ CD38 activity and NAD+ stimulation inhibited cell growth, markedly altered cell morphology, and induced

A

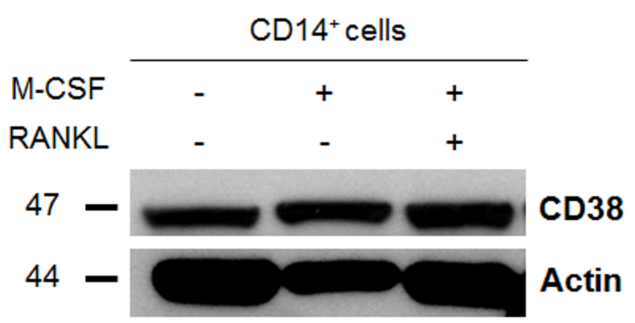

B

Day 0

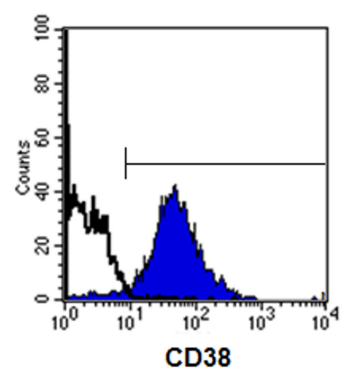

Day 7
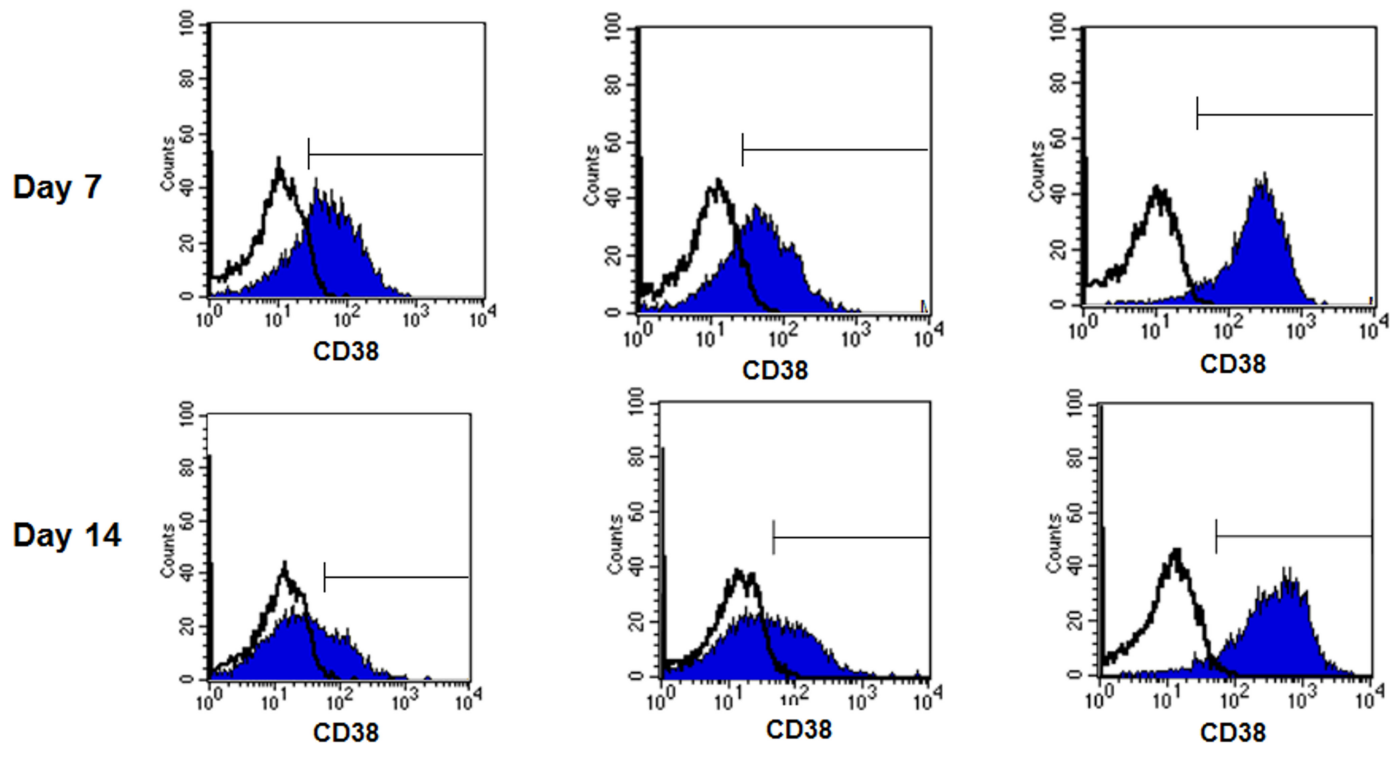

CNT

ATRA $0.1 \mathrm{nM}$

ATRA $20 \mathrm{nM}$

Figure 3: CD38 expression during in vitro osteoclastogenesis. (A) CD38 expression was evaluated on CD14 ${ }^{+}$cells purified from PBMCs of HDs by an immunomagnetic method and seeded $\left(1 \times 10^{6}\right.$ cells $)$ in Petri dishes in $\alpha$ MEM at $10 \%$ FBS with rhM-CSF $25 \mathrm{ng} / \mathrm{ml}$, in presence or absence rhRANKL $60 \mathrm{ng} / \mathrm{ml}$. After 21 days of culture, cells were collected and analyzed by Western Blot. $\beta$-actin was used as internal control. (B) A time-course analysis of CD38 expression was performed during OC differentiation. CD38 expression was analyzed by flow-cytometry on $\mathrm{CD} 14^{+}$cells at seeding (day 0$)$; cells $\left(1 \times 10^{6} / \mathrm{ml}\right)$ were cultured in 6 -weel plates in $\alpha \mathrm{MEM}$ at $10 \%$ FBS with rhMCSF $25 \mathrm{ng} / \mathrm{ml}$ and rhRANKL $60 \mathrm{ng} / \mathrm{ml}$, in presence or absence of ATRA $(0.1$ and $20 \mathrm{nM})$. On day 7 and 14 of culture period, cells were collected and CD38 expression was evaluated by flow-cytometry. (Graph represent flow-cytometry data from a representative experiment. Open histograms: negative control, blue histograms: anti-CD38). 
significant increases in alkaline phosphatase activity and osteocalcin mRNA, indicating that the nucleotide may act as a differentiation signal [29]. The analysis of gene expression of CD38 by MM PCs did not show any correlation with the presence of osteolytic lesions in MM patients (Toscani D et al unpublished data).

In line with the literature $[6,7]$, the immunohistochemistry data showed that CD38 was expressed at high levels by PCs of patients with monoclonal gammopathies. On the other hand, OBs and OCs were negative for CD38 expression. MM cells also expressed CD31, CD39 and CD73 at variable levels, as previously reporte $[10,33,34]$. Interestingly, we found that OBs were positive for CD73 but expressed low levels of CD39 and did not express CD31. Previous studies showed that osteoblastic differentiation of hMSCs was induced by ATP degradation mediated by CD73 and CD39 expression on hMSC membrane [35], and that osteoblastogenesis is characterized by a stability of surface CD73, an increased
CD203a expression and a lack of cell surface expression of CD38 and CD157 [36]. Lastly, endothelial cells express high level of CD31 and CD39, CD73 at variable levels while express neither CD38 nor CD203a. The distribution of the analyzed ectoenzymes within the MM microenvironment could clarify the involvement of bone cells in the ADO-mediated stimulation of growth and survival of MM cells.

Thereafter, we investigated the possible role of CD38 in human OC differentiation by the analysis of CD38 expression on monocytes and OC. Both cell types expressed CD38 in the cytoplasm in line with literature data [30, 31]. Faust J et al. [30] found that CD38 was expressed by OC-like cells, whereas a more recent study reported that mature OCs express CD38 [31]. Moreover, we checked flow cytometry expression of CD38 during in vitro osteoclastogenesis from $\mathrm{CD} 14^{+}$cells. We found that monocytes expressed CD38 at seeding but it was lost during OC differentiation. Confocal microscopy confirmed
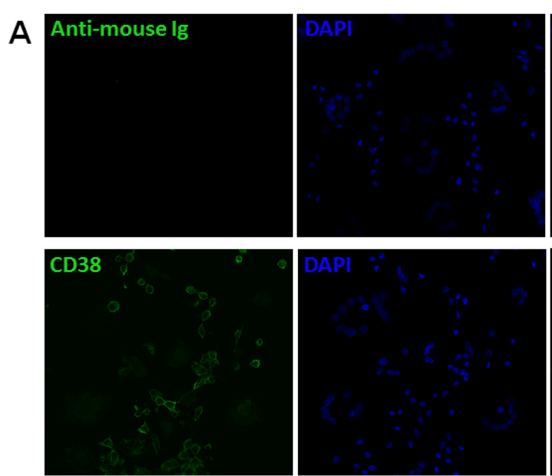
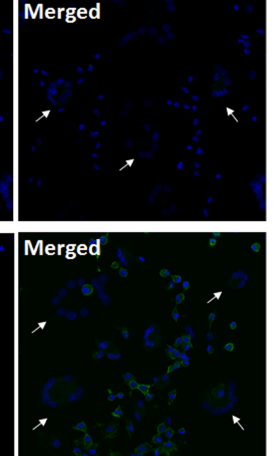
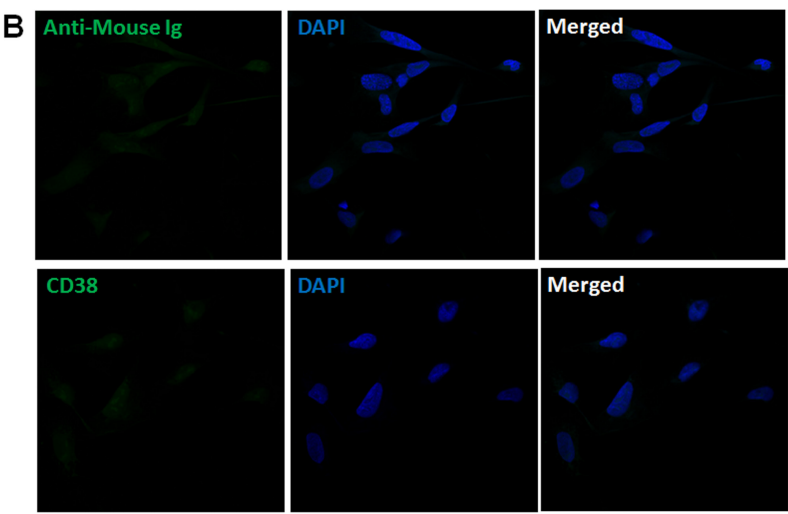

C
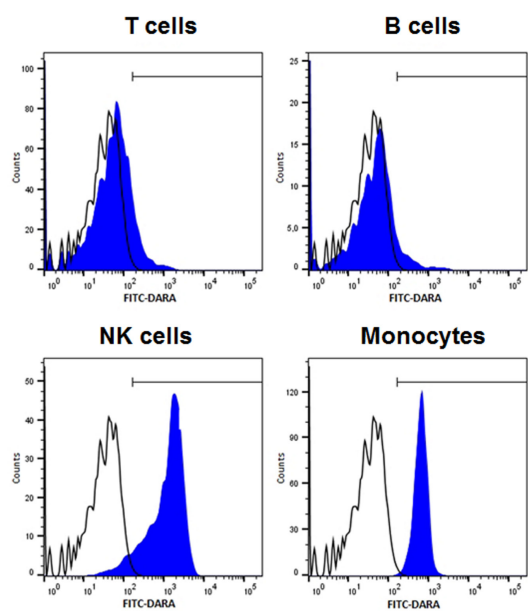

Figure 4: Anti-CD38 monoclonal antibodies bind monocytes but not mature OCs. (A) OCs were differentiated from HD $\mathrm{CD}_{14}^{+}$cells, seeded on cover glasses, in 24-well plates, in $\alpha \mathrm{MEM}$ with $10 \% \mathrm{FBS}$, rhM-CSF $25 \mathrm{ng} / \mathrm{ml}$ and $\mathrm{rhRANKL} 60 \mathrm{ng} / \mathrm{ml}$, for 21 days. (B) HOBIT cell line was seeded on cover glasses until the confluence in DMEM 10\% FBS. At the end of culture period, cells were stained with the primary antibody anti-CD38 IB4 followed by Alexa fluor-488-conjugated secondary antibody (lower images). The negative control samples were not incubated with primary antibody and are shown in the upper images. OCs were identified as multinucleated cells ( $\geq 3$ nuclei, DAPI stained after permeabilization) and indicated by arrows. (C) PBMCs isolated from 5 HDs were incubated with FITCconjugated DARA for $30 \mathrm{~min}$ at $4{ }^{\circ} \mathrm{C}$ and then stained for the expression of surface markers CD3, CD19, CD16 or CD14 to identify T cells, $\mathrm{B}$ cells, NK cells and monocytes, respectively. Flow cytometry data from a representative experiment are reported in the graph. (Open histograms: negative control; blue histograms: FITC-DARA). 
A
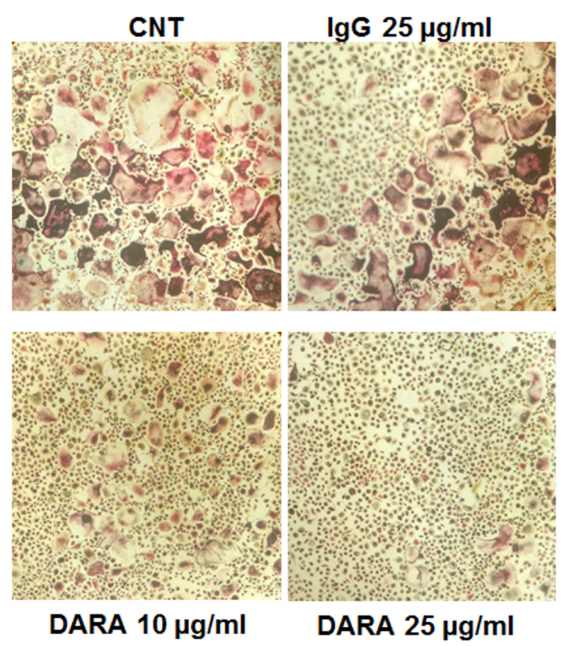

B

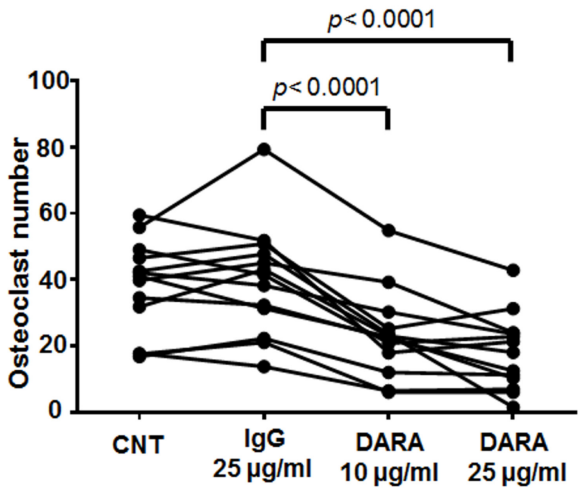

Day 0
Day 10

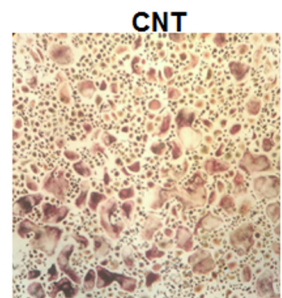

lgG $25 \mu \mathrm{g} / \mathrm{ml}$

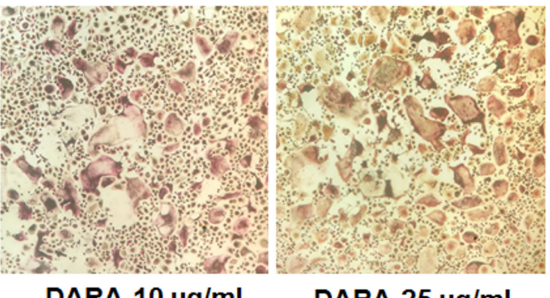

DARA $10 \mu \mathrm{g} / \mathrm{ml}$

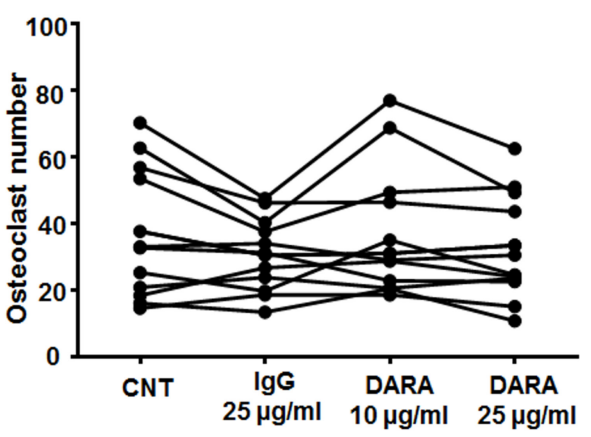

Day 10

C

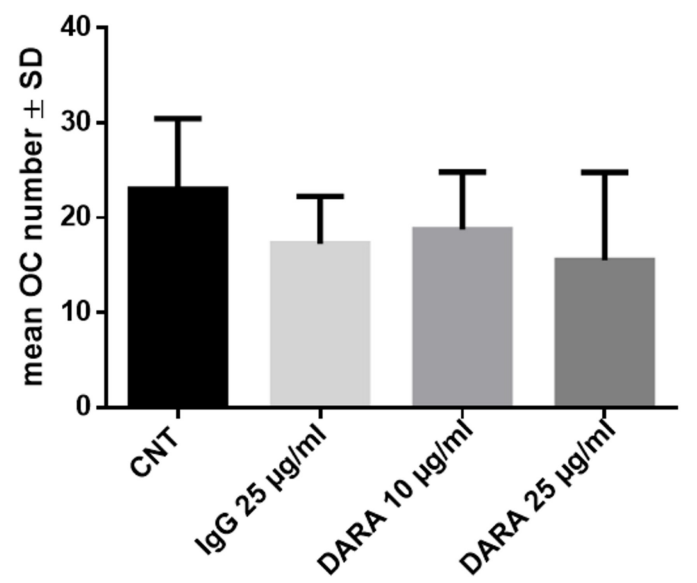

Figure 5: DARA inhibits in vitro osteoclastogenesis from MNCs but not from CD14 ${ }^{+}$cells affecting early $\mathrm{OC}$ progenitors. (A, B) OCs were differentiated from MNCs of 13 MM patients, in the presence of DARA or isotype control IgG and then cultured for 21 days. DARA treatment was performed either at seeding (day 0) or after 10 days of culture (day 10). The OCs were identified and counted by light microscopy at the end of the culture period as multinucleated ( $\geq 3$ nuclei) cells, positive for tartrate resistant acid phosphatase (TRAP) assay. Graphs represent the mean OC number of each individual patient ( $p$ calculated by two-tailed, paired Student's $t$-test) of 13 independent experiments. (C) Osteoclastogenesis was performed from purified CD14 $4^{+}$cells obtained from BM samples of MM patients cultured with rhM-CSF $25 \mathrm{ng} / \mathrm{ml}$ and rhRANKL $60 \mathrm{ng} / \mathrm{ml}$ for 21 days, in the presence of DARA (10-25 $\mu \mathrm{g} / \mathrm{ml})$ or isotype control IgG. The OCs were identified and counted by light microscopy at the end of the culture period as multinucleated ( $\geq 3$ nuclei) cells, positive for TRAP assay. 
A

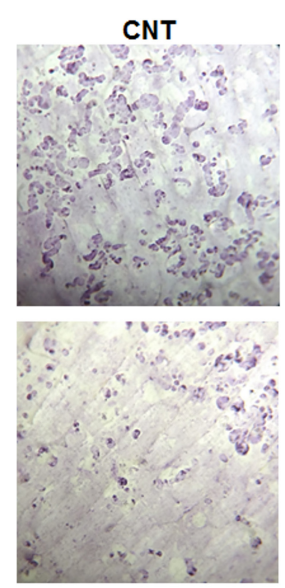

DARA $10 \mu \mathrm{g} / \mathrm{ml}$
14 days

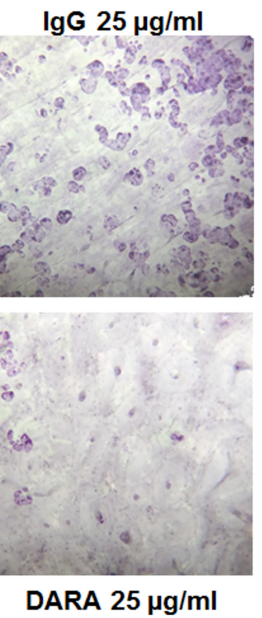

B

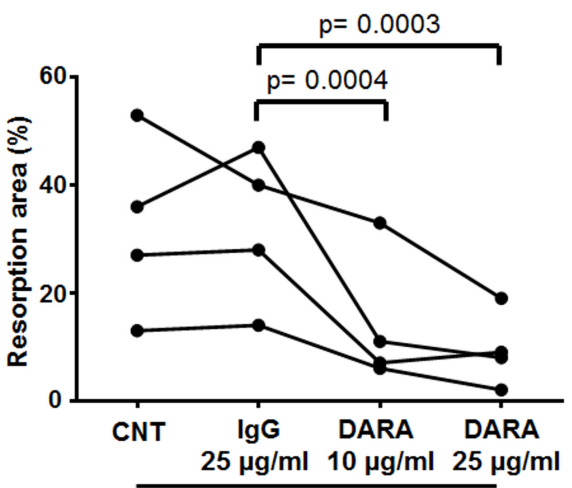

14 days
21 days

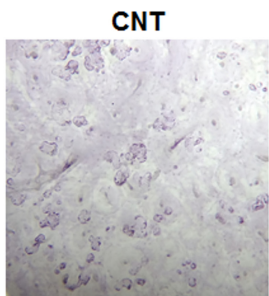

$\lg \mathbf{2} 25 \mathrm{gg} / \mathrm{ml}$

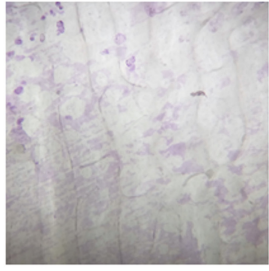

DARA $10 \mu \mathrm{g} / \mathrm{ml}$
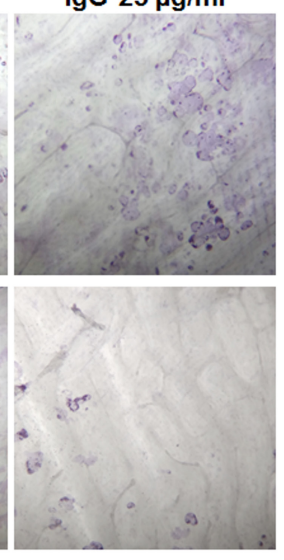

DARA $25 \mu \mathrm{g} / \mathrm{ml}$

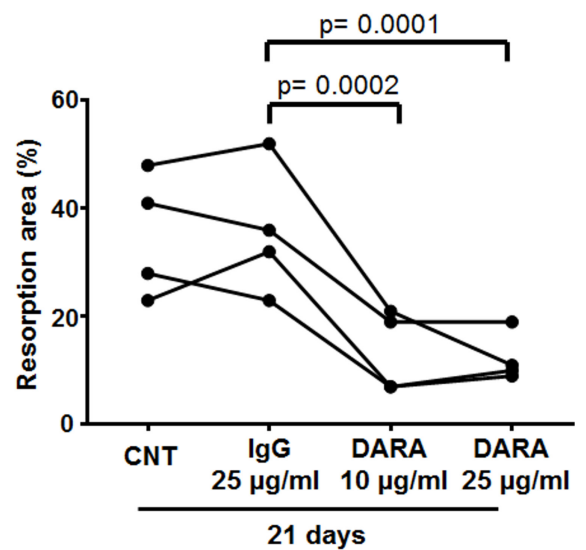

C

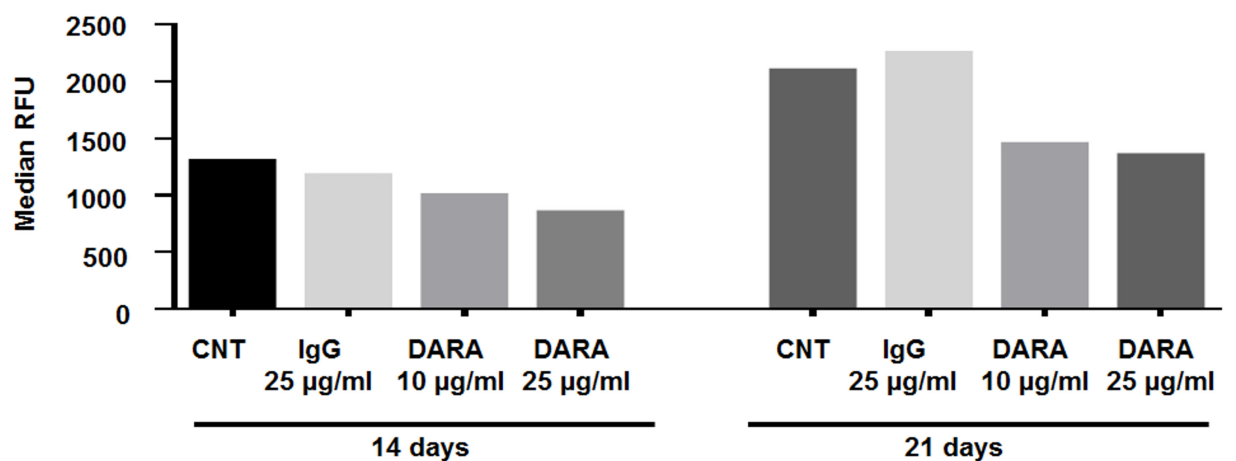

Figure 6: DARA decreases bone resorption area and OC activity. (A, B) OCs were differentiated from MNCs of 8 MM patients in the presence of DARA or isotype control IgG and then cultured for 14 days $(n=4)$ and 21 days $(n=4)$ on bone slices. Pit area was observed under light microscope $(10 \times)$. Data are expressed as the percentage of resorption area of 8 independent experiments (at least 3 replicated each condition). Symbols connected by a line represent cultures from the same donor. $p$ calculated using a two-tailed, paired Student's $t$-test. (C) OC bone resorption activity was assessed by the OsteoLyse ${ }^{\mathrm{TM}}$ Assay. MM BM MNCs were seeded on a 96-well plate coated with fluorophore-derivatized human bone matrix and cultured for 14 or 21 days in $\alpha \mathrm{MEM}$ with $10 \% \mathrm{FBS}$, rhM-CSF $25 \mathrm{ng} / \mathrm{ml}$ and rhRANKL $60 \mathrm{ng} / \mathrm{ml}$ in the presence of DARA $(10-25 \mu \mathrm{g} / \mathrm{ml})$ or isotype control IgG. The resorptive activity of the OCs was measured by sampling the cell culture supernatant at the end of differentiation, mixed with a Fluorophore-Releasing Reagent in a second 96-well assay plate and counted using time-resolved fluorescence by EnSpire Multimode Plate Reader 2300. Graph bars represent the median RFU on day 14 and day 21 of OC differentiation from a representative experiment. 
this evidence. This is in line with what Pfister $\mathrm{M}$ et al. [37] reported on macrophage differentiation. Overall these results indicate that, other than in PCs, the cell surface CD38 expression is limited to early osteoclast progenitors. Consequently, these cell types could be the target of antiCD38 therapeutic Abs.

DARA, a human anti-CD38 IgG1 $\kappa$ antibody, has shown encouraging results in the treatment of MM [19, 22, 38, 39]. The main mechanisms by which DARA exerts its anti-myeloma effect are ADCC and CDC
[22, 38]. However, DARA effects on bone cells and on $\mathrm{MM}$-induced bone remodelling alterations are still unknown. Thus, based on CD38 expression profiling, we evaluated the effect of DARA on osteoclastogenesis. The flow-cytometry analysis showed that DARA binds monocytes and our in vitro experiments indicated that DARA treatment significantly reduced the number of TRAP-positive multinucleated OCs compared to IgG isotype controls when it was added on day 0 but not on day 10 , consistent with the expression profiling of

A
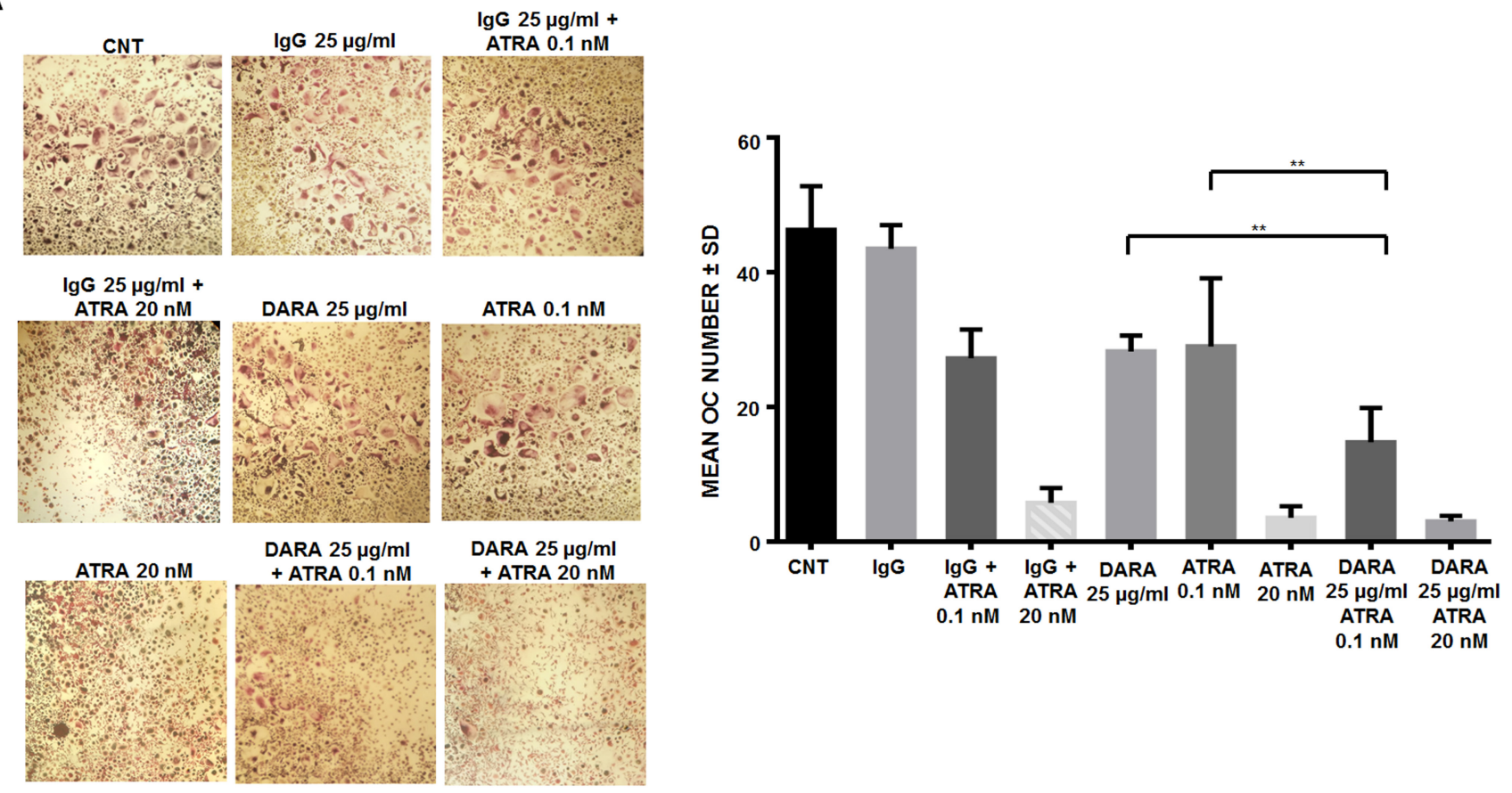

DARA $25 \mu \mathrm{g} / \mathrm{ml}$
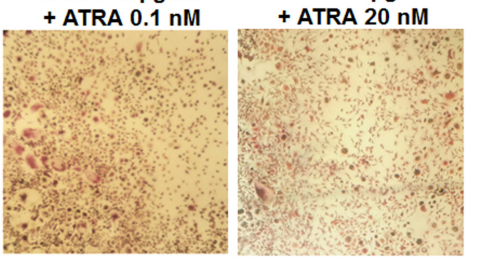

B
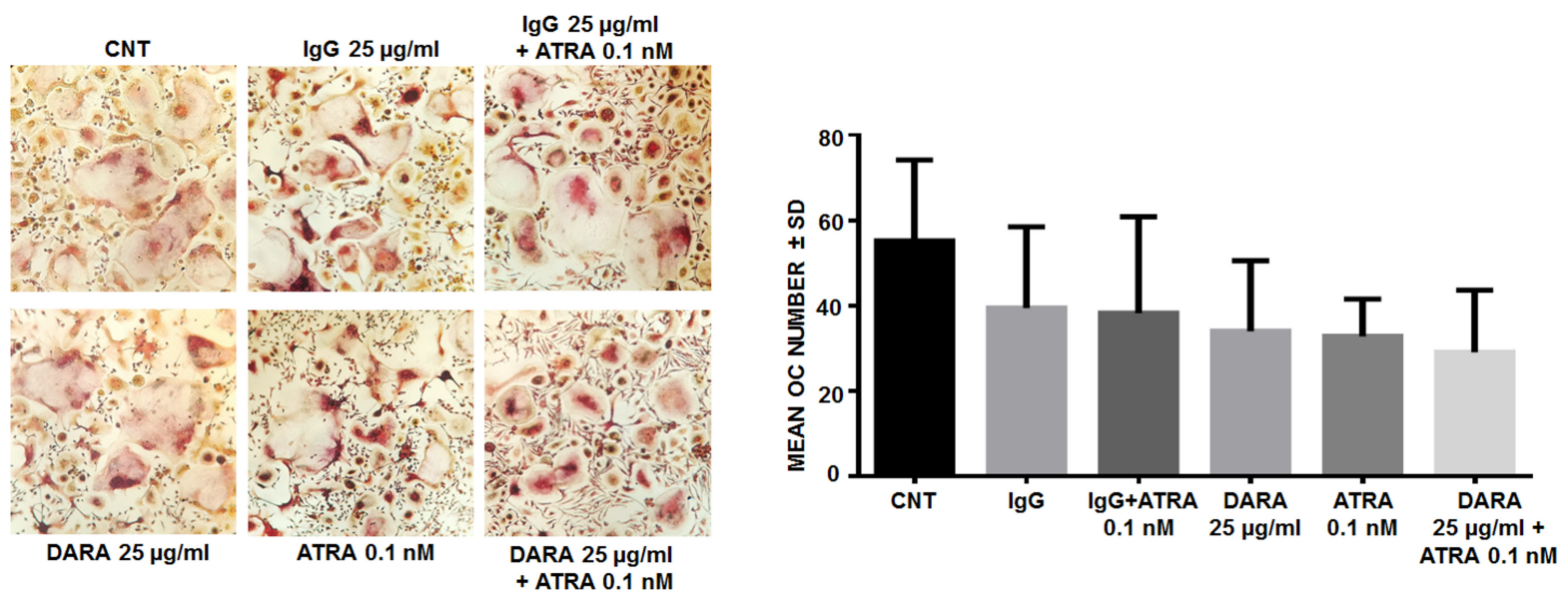

Figure 7: ATRA treatment increases DARA effects on OC differentiation. (A) OCs were differentiated from MNCs of MM patients in the presence of DARA $25 \mu \mathrm{g} / \mathrm{ml}$ or isotype control $\mathrm{IgG}$, with or without ATRA at $0.1 \mathrm{nM}$ and $20 \mathrm{nM}$, or vehicle (DMSO), for 21 days. The OCs were identified and counted by light microscopy at the end of the culture period as multinucleated ( $\geq 3$ nuclei) cells positive for TRAP assay. Graph bars represent the mean \pm SD OC number for each well ( $p$ calculated by one-way ANOVA followed by Dunnett's multiple comparison test of a representative experiment $* *=p<0.001)$. (B) Osteoclastogenesis was performed from purified CD14 ${ }^{+}$cells obtained from BM samples of MM patients cultured with rhM-CSF $25 \mathrm{ng} / \mathrm{ml}$ and rhRANKL $60 \mathrm{ng} / \mathrm{ml}$ for 21 days, in the presence of DARA $(25 \mu \mathrm{g} / \mathrm{ml})$ or isotype control IgG, with or without ATRA $(0.1 \mathrm{nM})$, or vehicle (DMSO), for 21 days. The OCs were identified and counted by light microscopy at the end of the culture period as multinucleated ( $\geq 3$ nuclei) cells, positive for TRAP assay. 
CD38 observed by flow cytometry. Furthermore, DARA significantly reduced the area of osteoclast bone resorption pits and OC activity. Interestingly, we showed that DARA inhibited OC formation only when OCs were differentiated from total MNCs but not from isolated $\mathrm{CD}_{14}{ }^{+}$cells, suggesting that DARA effect on osteoclastogenesis was mediated by the effector cells, as shown for the anti-MM activity [22]. In support of our findings, a recent study from An $\mathrm{G}$ et al. [31] showed that a different humanized Ab specific for CD38, namely SAR 650984, had no effect on osteoclastogenesis from isolated $\mathrm{CD} 14^{+}$cells [31].

More recently, Horenstein AL et al. [26] have shown that DARA ligation on MM cells was followed by aggregation, polarization, and release of MVs, which express several molecules clustered in lipid domains on their surface, including both CD38 and DARA. However, the fate of MVs is still unknown. Chillemi A et al. [40] also showed a tendency of DARA-labeled MVs to cluster around NK cells and monocytes, since DARA shows a high affinity to Fc receptors of immune cell types [40]. Relying on these data, we investigated the involvement of DARAinduced MVs from MM cells in OC formation. We did not find any appreciable effects on in vitro osteoclastogenesis in the presence of DARA-induced MVs compared to IgGinduced MVs. Overall, our in vitro evidence indicates that the anti osteoclastogenic effect of DARA is mainly due to its ability to bind monocytes and OC progenitors, and, consequently, to the activation of effector cells. Since literature data showed that ATRA treatment increased DARA anti-MM effects, [23] we also tested the effect of DARA in combination with ATRA in osteoclastogenesis. High concentration of ATRA (20nM) enhanced CD38 expression on day 7 and 14 of OC differentiation, in line with that reported by Drach J et al. [41] on myeloid cells. On the other hand, low concentration of ATRA $(0.1 \mathrm{nM})$ had no effect on CD38 expression on OC progenitors, but it decreased the number of TRAP positive multinucleate OCs when used in combination with DARA, compared with the single agent treatment supporting the possibility to use ATRA to enhance DARA effect. This combinatory effect is not likely to be correlated to the modulation of CD38 expression on OC progenitors by ATRA that occurs only at high concentration. As reported in the literature, [42] a direct inhibitory effect of ATRA on RANKLstimulated osteoclastogenesis was shown and this mechanism could potentiate the effect of DARA on OC formation. Indeed, the combination ATRA plus DARA did not affect the number of OCs differentiated from purified $\mathrm{CD} 14^{+}$cells thus confirming the importance of effector cells and elucidating the effect of the combination. In conclusion, our findings define the expression profiling of CD38 and a panel of selected ectoenzymes and molecules in the bone niche of MM patients. Moreover, consistent with the CD38 expression profiling, we show that therapeutic anti-CD38 DARA significantly inhibits OC formation by targeting OC progenitors with a potential clinical relevance. On the other hand, CD38 was expressed by OBs at detectable levels, which bona fide rules out the possibility of cytotoxic events delivered by DARA. Taken together, these findings highlight the possibility of a role of CD38 during OC formation, which further supports the use of DARA as a treatment for bone destruction in MM patients.

\section{MATERIALS AND METHODS}

\section{Patients}

BM aspirates were obtained from $16 \mathrm{MM}$ consecutive patients, including 8 newly diagnosed (ND) (median age: 70 years, range: $57-86 ; 75 \%$ Female (F), 25\% Male (M); International Staging System (ISS): I = 12.5\%, $\mathrm{II}=12.5 \%$, III $=75 \%$ ) and 8 relapsed $(\mathrm{R})$ (median age: 76 years, range: $43-90 ; 38 \% \mathrm{~F}, 62 \% \mathrm{M}$; ISS: $\mathrm{I}=12.5 \%$, $\mathrm{II}=25 \%$, III $=62.5 \%$ ), to purify fresh $\mathrm{CD} 138^{+}$cells and evaluate the immunophenotypic profiling. Only samples with purity $>$ of $90 \%$ checked by flow cytometry (BD FACS Canto II with Diva software; Becton, Dickinson and Company (BD); Franklin Lakes, NJ) were tested.

A retrospective study of a total cohort of 51 patients with monoclonal gammopathies was performed including 25 patients with ND MM: median age 70 years range: $41-85 ; 36 \%$ F, 64\% M; ISS: I $=30 \%$, II $=22 \%$, III $=$ $48 \% ; 12$ with smoldering MM (SMM): median age: 70 years, range: $47-83$ years, 33\% F, 67\% M; and 14 with monoclonal gammopathy of uncertain significance (MGUS): median age: 71 years, range: 39-88 years; $64 \%$ F 36\% M; who had access to Hematology Unit of Parma from May 2011 to June 2015. Bone biopsies were obtained from iliac crest of each patients to perform immunohistochemistry for the following antigen: CD38, CD39, CD73, CD31, and CD203a.

Patient samples were obtained after informed consent, according to the Declaration of Helsinki. The study was included in a larger project on patients with monoclonal gammopathies, approved by the Institutional Ethical Review Board of our Hospital.

\section{Drugs}

DARA and isotype control IgG were provided by Janssen Pharmaceuticals (Spring House, PA, USA). ATRA was purchased from Sigma- Aldrich (Saint Louis, MO).

\section{Cells and cell culture conditions}

\section{PC purification}

$\mathrm{BM} \mathrm{CD}_{138^{+}}$cells were purified from total MNCs by an immuno-magnetic method using anti-CD138 mAb coated microbeads (MACS, Miltenyi Biotec; BergischGladbach, Germany), as previously described [43]. 


\section{DARA treatment on in vitro OC formation}

OCs were obtained either from total BM MNCs of MM patients, or purified $\mathrm{CD} 14^{+}$cells from $\mathrm{PBMCs}$ of 3 HDs. Cells were seeded in aMEM with $10 \%$ FBS, rhM-CSF $25 \mathrm{ng} / \mathrm{ml}$ and rhRANKL $60 \mathrm{ng} / \mathrm{ml}$ (Peprotech; Rocky Hill, NJ) in the presence of DARA $(10-25 \mu \mathrm{g} / \mathrm{ml})$ or isotype control IgG added to culture medium on day 0 or after 10 days, with or without ATRA (0.1-20 nM) or vehicle (DMSO) for 21 days, replacing half medium every $2-3$ days. BM MNCs were also incubated in the presence or absence of the CM (dilution ratio with $\alpha M E M$ with $10 \%$ FBS, rhMCSF $25 \mathrm{ng} / \mathrm{ml}$ and $\mathrm{rhRANKL} 60 \mathrm{ng} / \mathrm{ml}, 1: 3)$ of JJN3 and RPMI-8226 $\left(5 \times 10^{5}\right.$ cells $\left./ \mathrm{ml}\right)$ previously pre-treated with DARA $(10-25 \mu \mathrm{g} / \mathrm{ml})$ or isotype control $\mathrm{IgG}$ for $48 \mathrm{~h}$, and cultured for 21 days replacing half medium every 2-3 days. Each condition was performed at least in triplicate. For dose-finding experiment, BM MNCs were cultured in $\alpha M E M$ with $10 \%$ FBS, rhM-CSF $25 \mathrm{ng} / \mathrm{ml}$ and $\mathrm{rhRANKL} 60 \mathrm{ng} / \mathrm{ml}$ (Peprotech; Rocky Hill, NJ) in presence of ATRA (0.01 nM-200 nM), or vehicle (DMSO) for 21 days, replacing half medium every 2-3 days.

MVs isolation, tartrate resistant acid phosphatase (TRAP) and Osteoclastogenesis resorption assays. Methods are detailed in the Supplementary Methods.

\section{Flow cytometry assay}

The immunophenotype of primary BM CD138 cells, HMCLs and microenvironment cells was analyzed with the following mAbs:

CD38-APC (clone HIT2, code n. 560677, BD)

CD31-FITC (clone WM59, code n. 555445, BD)

CD39-APC (clone eBioA1, code n. 17-0399-41, eBioscence; San Diego, CA)

CD73-APC (clone CB73), produced in the Lab of one of the authors (FM) and FITC-conjugated by AcZon (Bologna, Italy) Goding)

CD203a-FITC (clone 3E8, kindly provided by J.

CD14-PE (clone M5E2, code n. 555398, BD).

\section{DARA binding on PBMCs}

PBMCs isolated from 5 HDs were washed in PBS containing $1 \% \mathrm{BSA}+\mathrm{NaN}_{3}$ and incubated with FITCconjugated DARA for $30 \mathrm{~min}$ at $4^{\circ} \mathrm{C}$. T cells, B cells, NK cells and monocytes were identified by expression of surface markers using the following mAbs produced in the Lab of one of the authors (FM) and conjugated by AcZon (Bologna, Italy), respectively: anti-CD3-PerCP Cy5.5 (clone CBT3G), CD19-APC (clone CB19), CD16APC (clone CB16) and CD14-APC (clone CB14). Cells were washed in PBS and acquired on FACS. Data were analyzed using FlowJo Software (TreeStar, Ashland, OR).

\section{Immunohistochemistry}

Patient bone biopsies were fixed in formalin at 10\%. Once fixed, the samples were embedded in paraffin, so as to allow the cut to the microtome thin sections $(3-6 \mu \mathrm{m})$. Bone biopsy sections were incubated with polyclonal rabbit Abs against CD38 (1:1.500) (code n. HPA022132, Sigma, Saint Louis, MO) or CD39 (1:70) (code n. 142111-AP, Proteintech, Manchester, UK), CD73 (1:1.000), CD31 (1:50), for $60 \mathrm{~min}$ at room temperature. Antibodies anti-CD31, CD73 and CD203a were produced in the Lab of one of the authors (FM). The staining was visualized using the UltraVision LP Large Volume Detection System HRP polymer (Thermo Scientific, Erembodegem, Belgium) according to the manifacture's specifications. A sample was considered positive if the target antigen was detected at least in the $50 \%$ of cells. Images were captured by DP22 digital camera (Olympus; Hamburg, Germany) and analyzed with the OLYMPUS Stream software, adjusting tone and contrast to ensure the best image quality.

\section{Western blot analysis}

These methodologies were detailed in Supplemental Methods section of Supplementary Data.

\section{Immunofluorescence confocal microscopy}

Immunofluorescence analysis was carried out to quantify CD38 expression on mature OCs, obtained from $\mathrm{HD} \mathrm{CD} 14^{+}$cells. Cells $\left(1.2 \times 10^{6} /\right.$ well) were cultured in 24-well plates on $\varnothing 12 \mathrm{~mm}$ cover glasses (Thermo Scientific), in $\alpha \mathrm{MEM}$ with $10 \% \mathrm{FBS}$, rhM-CSF $25 \mathrm{ng}$ / $\mathrm{ml}$ and rhRANKL $60 \mathrm{ng} / \mathrm{ml}$, for 21 days, replacing half medium every 2-3 days. At the end of culture period, cells were reacted at $4^{\circ} \mathrm{C}$ with the primary $\mathrm{mAb}$ anti-CD38 (clone IB4, produced in the Lab of one of the authors (FM) for $1 \mathrm{~h}$. After rinsing with PBS, goat anti-mouse IgG $(\mathrm{H}+\mathrm{L})$ conjugated with Alexa Fluor 488 secondary Ab (code n. 115-545-003, Jackson ImmunoResearch Laboratories, West Grove, PA) was added for 30 min at $4^{\circ} \mathrm{C}$. The negative control samples were not incubated with primary antibody. After extensive washings, the cells were fixed with paraformaldehyde $\left(2 \%\right.$ in PBS, 15 min at $\left.4{ }^{\circ} \mathrm{C}\right)$. DNA was visualized after permeabilization with $0.2 \%$ Triton $\mathrm{X}-100$ detergent $\left(5 \mathrm{~min}\right.$ at $4^{\circ} \mathrm{C}$ ) and successive staining with DAPI. The same protocol was used to quantify CD38 expression on HOBIT cell line. The confocal imaging was performed on a TCS SP5 laser scanning confocal microscope with 4 lasers (Leica Microsystems; Wetzlar, Germany). 


\section{Statistical analysis}

Data were expressed as means \pm standard deviation (SD) or medians. Two-tailed, paired Student's $t$-test or one-way ANOVA followed by Dunnett's multiple comparison test were used to test significant differences. In all cases, $p<0.05$ was considered significant. GraphPad Prism 6.1 ${ }^{\mathrm{TM}}$ (GraphPad Software Inc., La Jolla, CA, USA) was used for all the statistical analyses.

\section{Abbreviations}

MM: Multiple myeloma; PC: Plasma cell; OCs: Osteoclasts; OBs: Osteoblasts; BM: Bone marrow; ADO: Adenosine; DARA: Daratumumab; mAb: Monoclonal antibody; CDC: Complement-dependent citotoxicity; ADCC: Antibody-dependent cell-mediated citotoxicity; ADCP: Antibody-dependent cellular phagocytosis; ATRA: all-trans retinoic acid; MVs: Microvesicles; ND: Newly diagnosed; F: Female; M: Male; ISS: International staging system; SMM: Smoldering MM; MGUS: Monoclonal gammopathy of uncertain significance; MNCs: Mononuclear cells; PBMC: Peripheral blood mononuclear cell; HDs: Healthy donors; CM: Conditioned media; SD: Standard deviation; TRAP: Tartrate resistant acid phosphatase; HMCLs: Human myeloma cell lines; RFU: Relative fluorescence unit.

\section{Authors' contributions}

F.C., D.T. and M.B. collected samples and performed experiments.

A.C., R.V., C.S. and S.B. performed the flow cytometry analysis. patients.

F.A., B.D.P. and N.G. provide clinical data and

V. Q., V. M., E.M., C.M. and C.C.: performed the immunohistochemical analyses on BM samples.

N.G. and F.M. designed the research, N.G. analyzed results, F.C., D.T. A.L.H. and N.G. wrote the paper.

C.F., D.T. and F.A. read, provided comments, and approved the final version of the manuscript.

\section{ACKNOWLEDGMENTS}

The authors would like to thank Dirce Gennari for her technical support.

\section{CONFLICTS OF INTEREST}

N.G and F.M. received a research grant from Janssen Pharmaceutical.

\section{FUNDING}

This work was supported in part by a grant from the Associazione Italiana per la Ricerca sul Cancro (AIRC)
IG2014 n.15531 (NG), two fellowships Fondazione Italiana per la Ricerca sul Cancro ID 16462 (DT) and ID 18152 (MB), a fellowship from ParmAIL (VM); FM was supported by grants from the Fondazione CRT (Torino, Italy), from Compagnia di San Paolo (grant to V. Pistoia, Genova, Italy) and from the Fondazione Ricerca Molinette (Torino, Italy).

\section{REFERENCES}

1. Roodman GD. Role of the bone marrow microenvironment in multiple myeloma. J Bone Miner Res. 2002; 17:1921-1925.

2. Giuliani N, Colla S, Rizzoli V. New insight in the mechanism of osteoclast activation and formation in multiple myeloma: focus on the receptor activator of NF-kappaB ligand (RANKL). Exp Hematol. 2004; 32:685-691.

3. Giuliani N, Rizzoli V, Roodman GD. Multiple myeloma bone disease: Pathophysiology of osteoblast inhibition. Blood. 2006; 108:3992-3996.

4. Mahindra A, Hideshima T, Anderson KC. Multiple myeloma: biology of the disease. Blood Rev. 2010; 24:S5-11.

5. Roodman GD. Pathogenesis of myeloma bone disease. Leukemia. 2009; 23:435-441.

6. Lin P, Owens R, Tricot G, Wilson CS. Flow cytometric immunophenotypic analysis of 306 cases of multiple myeloma. Am J Clin Pathol. 2004; 121:482-488.

7. Santonocito AM, Consoli U, Bagnato S, Milone G, Palumbo GA, Di Raimondo F, Stagno F, Guglielmo P, Giustolisi R. Flow cytometric detection of aneuploid CD38(++) plasmacells and CD19(+) B-lymphocytes in bone marrow, peripheral blood and PBSC harvest in multiple myeloma patients. Leuk Res. 2004; 28:469-477.

8. Mehta K, Shahid U, Malavasi F. Human CD38, a cellsurface protein with multiple functions. FASEB J. 1996; 10:1408-1417.

9. Malavasi F, Deaglio S, Funaro A, Ferrero E, Horenstein AL, Ortolan E, Vaisitti T, Aydin S. Evolution and function of the ADP ribosyl cyclase/CD38 gene family in physiology and pathology. Physiol Rev. 2008; 88:841-886.

10. Chillemi A, Zaccarello G, Quarona V, Lazzaretti M, Martella E, Giuliani N, Ferracini R, Pistoia V, Horenstein AL, Malavasi F. CD38 and bone marrow microenvironment. Front Biosci (Landmark Ed). 2014; 19:152-162.

11. Deaglio S, Morra M, Mallone R, Ausiello CM, Prager E, Garbarino G, Dianzani U, Stockinger H, Malavasi F. Human CD38 (ADP-ribosyl cyclase) is a counter-receptor of CD31, an Ig superfamily member. J Immunol. 1998; 160:395-402.

12. Aarhus R, Graeff RM, Dickey DM, Walseth TF, Lee HC. ADP-ribosyl cyclase and CD38 catalyze the synthesis of a calcium-mobilizing metabolite from NADP. J Biol Chem. $1995 ; 270: 30327-30333$. 
13. Horenstein AL, Chillemi A, Zaccarello G, Bruzzone S, Quarona V, Zito A, Serra S, Malavasi F. A CD38/CD203a/ CD73 ectoenzymatic pathway independent of CD39 drives a novel adenosinergic loop in human $\mathrm{T}$ lymphocytes. Oncoimmunology. 2013; 2:e26246.

14. Funaro A, Horenstein AL, Calosso L, Morra M, Tarocco RP, Franco L, De Flora A, Malavasi F. Identification and characterization of an active soluble form of human CD38 in normal and pathological fluids. Int Immunol. 1996; 8:1643-1650.

15. Zumaquero E, Munoz P, Cobo M, Lucena G, Pavon EJ, Martin A, Navarro P, Garcia-Perez A, Ariza-Veguillas A, Malavasi F, Sancho J, Zubiaur M. Exosomes from human lymphoblastoid B cells express enzymatically active CD38 that is associated with signaling complexes containing CD81, Hsc-70 and Lyn. Exp Cell Res. 2010; 316:2692-2706.

16. Sun L, Iqbal J, Dolgilevich S, Yuen T, Wu XB, Moonga BS, Adebanjo OA, Bevis PJ, Lund F, Huang CL, Blair HC, Abe E, Zaidi M. Disordered osteoclast formation and function in a CD38 (ADP-ribosyl cyclase)-deficient mouse establishes an essential role for CD38 in bone resorption. FASEB J. 2003; 17:369-375.

17. Sun L, Adebanjo OA, Moonga BS, Corisdeo S, Anandatheerthavarada HK, Biswas G, Arakawa T, Hakeda Y, Koval A, Sodam B, Bevis PJ, Moser AJ, Lai FA, et al. CD38/ADP-ribosyl cyclase: A new role in the regulation of osteoclastic bone resorption. J Cell Biol. 1999; 146:1161-1172.

18. Sun L, Adebanjo OA, Koval A, Anandatheerthavarada HK, Iqbal J, Wu XY, Moonga BS, Wu XB, Biswas G, Bevis PJ, Kumegawa M, Epstein S, Huang CL, et al. A novel mechanism for coupling cellular intermediary metabolism to cytosolic $\mathrm{Ca} 2+$ signaling via CD38/ADP-ribosyl cyclase, a putative intracellular NAD+ sensor. FASEB J. 2002; 16:302-314.

19. van de Donk NW, Moreau P, Plesner T, Palumbo A, Gay F, Laubach JP, Malavasi F, Avet-Loiseau H, Mateos MV, Sonneveld P, Lokhorst HM, Richardson PG. Clinical efficacy and management of monoclonal antibodies targeting CD38 and SLAMF7 in multiple myeloma. Blood. 2016; 127:681-695.

20. Lokhorst HM, Plesner T, Laubach JP, Nahi H, Gimsing P, Hansson M, Minnema MC, Lassen U, Krejcik J, Palumbo A, van de Donk NW, Ahmadi T, Khan I, et al. Targeting CD38 with Daratumumab Monotherapy in Multiple Myeloma. N Engl J Med. 2015; 373:1207-1219.

21. Moreau P, Touzeau C. Multiple myeloma: from front-line to relapsed therapies. American Society of Clinical Oncology educational book/ASCO Am Soc Clin Oncol Educ Book. 2015:e504-511.

22. de Weers M, Tai YT, van der Veer MS, Bakker JM, Vink T, Jacobs DC, Oomen LA, Peipp M, Valerius T, Slootstra JW, Mutis T, Bleeker WK, Anderson KC, et al. Daratumumab, a novel therapeutic human CD38 monoclonal antibody, induces killing of multiple myeloma and other hematological tumors. J Immunol. 2011; 186:1840-1848

23. Nijhof IS, Groen RW, Lokhorst HM, van Kessel B, Bloem AC, van Velzen J, de Jong-Korlaar R, Yuan H, Noort WA, Klein SK, Martens AC, Doshi P, Sasser K, et al. Upregulation of CD38 expression on multiple myeloma cells by all-trans retinoic acid improves the efficacy of daratumumab. Leukemia. 2015; 29:2039-2049.

24. Milani G, Lana T, Bresolin S, Aveic S, Pasto A, Frasson C, Te Kronnie G. Expression Profiling of Circulating Microvesicles Reveals Intercellular Transmission of Oncogenic Pathways. Mol Cancer Res. 2017.

25. Becker A, Thakur BK, Weiss JM, Kim HS, Peinado H, Lyden D. Extracellular Vesicles in Cancer: Cell-to-Cell Mediators of Metastasis. Cancer Cell. 2016; 30:836-848.

26. Horenstein AL, Chillemi A, Quarona V, Zito A, Roato I, Morandi F, Marimpietri D, Bolzoni M, Toscani D, Oldham RJ, Cuccioloni M, Sasser AK, Pistoia V, et al. $\mathrm{NAD}(+)$-Metabolizing Ectoenzymes in Remodeling TumorHost Interactions: The Human Myeloma Model. Cells. 2015; 4:520-537.

27. Chillemi A, Zaccarello G, Quarona V, Ferracin M, Ghimenti C, Massaia M, Horenstein AL, Malavasi F. AntiCD38 antibody therapy: windows of opportunity yielded by the functional characteristics of the target molecule. Mol Med. 2013; 19:99-108.

28. Krejcik J, Casneuf T, Nijhof IS, Verbist B, Bald J, Plesner T, Syed K, Liu K, van de Donk NW, Weiss BM, Ahmadi T, Lokhorst HM, Mutis T, et al. Daratumumab depletes CD38+ immune regulatory cells, promotes T-cell expansion, and skews T-cell repertoire in multiple myeloma. Blood. 2016; 128:384-394.

29. Romanello M, Padoan M, Franco L, Veronesi V, Moro L, D'Andrea P. Extracellular $\mathrm{NAD}(+)$ induces calcium signaling and apoptosis in human osteoblastic cells. Biochemical and Biochem Biophys Res Commun. 2001; 285:1226-1231.

30. Faust J, Hunt P, Scully S, Shalhoub V. Multiple myeloma cells and cells of the human osteoclast lineage share morphological and cell surface markers. J Cell Biochem. 1998; 71:559-568.

31. An G, Acharya C, Feng X, Wen K, Zhong M, Zhang L, Munshi NC, Qiu L, Tai YT, Anderson KC. Osteoclasts promote immune suppressive microenvironment in multiple myeloma: therapeutic implication. Blood. 2016.

32. Horenstein AL, Quarona V, Toscani D, Costa F, Chillemi A, Pistoia V, Giuliani N, Malavasi F. Adenosine Generated in the Bone Marrow Niche Through a CD38-Mediated Pathway Correlates with Progression of Human Myeloma. Mol Med. 2016; 22.

33. Deaglio S, Mallone R, Baj G, Arnulfo A, Surico N, Dianzani U, Mehta K, Malavasi F. CD38/CD31, a receptor/ ligand system ruling adhesion and signaling in human leukocytes. Chem Immunol. 2000; 75:99-120. 
34. Vallario A, Chilosi M, Adami F, Montagna L, Deaglio S, Malavasi F, Caligaris-Cappio F. Human myeloma cells express the CD38 ligand CD31. Br J Haematol. 1999; 105:441-444.

35. Ciciarello M, Zini R, Rossi L, Salvestrini V, Ferrari D, Manfredini R, Lemoli RM. Extracellular purines promote the differentiation of human bone marrow-derived mesenchymal stem cells to the osteogenic and adipogenic lineages. Stem Cells Dev. 2013; 22:1097-1111.

36. Quarona V, Ferri V, Chillemi A, Bolzoni M, Mancini C, Zaccarello G, Roato I, Morandi F, Marimpietri D, Faccani G, Martella E, Pistoia V, Giuliani N, et al. Unraveling the contribution of ectoenzymes to myeloma life and survival in the bone marrow niche. Ann N Y Acad Sci. 2015; 1335:10-22.

37. Pfister M, Ogilvie A, da Silva CP, Grahnert A, Guse AH, Hauschildt S. NAD degradation and regulation of CD38 expression by human monocytes/macrophages. Eur J Biochem. 2001; 268:5601-5608.

38. van der Veer MS, de Weers M, van Kessel B, Bakker JM, Wittebol S, Parren PW, Lokhorst HM, Mutis T. Towards effective immunotherapy of myeloma: enhanced elimination of myeloma cells by combination of lenalidomide with the human CD38 monoclonal antibody daratumumab. Haematologica. 2011; 96:284-290.

39. Nijhof IS, Groen RW, Noort WA, van Kessel B, de Jong-Korlaar R, Bakker J, van Bueren JJ, Parren PW, Lokhorst HM, van de Donk NW, Martens AC, Mutis T.
Preclinical Evidence for the Therapeutic Potential of CD38Targeted Immuno-Chemotherapy in Multiple Myeloma Patients Refractory to Lenalidomide and Bortezomib. Clin Cancer Res. 2015; 21:2802-2810.

40. Chillemi A, Quarona V, Zito A, Morandi F, Marimpietri D, Cuccioloni M, Robert OJ, Mark CS, Bolzoni M, Toscani D, Pistoia V, Giuliani N, Horenstein AL, et al. Generation and Characterization of Microvesicles after Daratumumab Interaction with Myeloma Cells. Blood. 2015; 126.

41. Drach J, McQueen T, Engel H, Andreeff M, Robertson KA, Collins SJ, Malavasi F, Mehta K. Retinoic acid-induced expression of CD38 antigen in myeloid cells is mediated through retinoic acid receptor-alpha. Cancer Res. 1994; 54:1746-1752.

42. Hu L, Lind T, Sundqvist A, Jacobson A, Melhus H. Retinoic acid increases proliferation of human osteoclast progenitors and inhibits RANKL-stimulated osteoclast differentiation by suppressing RANK. PLoS One. 2010; 5:e13305.

43. Storti P, Marchica V, Airoldi I, Donofrio G, Fiorini E, Ferri V, Guasco D, Todoerti K, Silbermann R, Anderson JL, Zhao W, Agnelli L, Bolzoni M, et al. Galectin-1 suppression delineates a new strategy to inhibit myeloma-induced angiogenesis and tumoral growth in vivo. Leukemia. 2016. 